\title{
Energy Management Strategy for a Battery-Diesel Stand-Alone System with Distributed PV Generation based on Grid Frequency Modulation
}

\author{
Authors: Andoni Urtasun, Pablo Sanchis, David Barricarte, and Luis Marroyo
}

The authors are from the Department of Electrical and Electronic Engineering, Public University of Navarra, Pamplona 31006, Spain (e-mail: andoni.urtasun@unavarra.es; pablo.sanchis@unavarra.es; luisma@unavarra.es) and from the Department of PV Solar Energy, Ingeteam Power Technology, Sarriguren 31621, Spain (e-mail: david.barricarte@, ingeteam.com).

Corresponding author: Andoni Urtasun, address: C/Arrosadia s/n, Planta Baja, 31006 (Pamplona, Spain), email: andoni.urtasun@unavarra.es, Phone: 0034948168934.

Abstract: A hybrid PV-Battery-Diesel configuration is very attractive for stand-alone systems in terms of cost and reliability. In many applications, the battery and the diesel generator are centralized and generate the AC grid while the PV generators and loads are distributed and are connected to the grid. However, in these cases, long communication cables are required in order to reduce the PV power when the battery is fully charged. This paper proposes an energy management strategy which makes it possible to avoid the use of communication cables, rendering the system simpler, cheaper and more reliable. The strategy dictates that should a power reduction be required, the battery inverter increases the grid frequency. This is detected by the PV inverters, which continuously reduce their power in order to prevent the battery from overcharge or over-current. The strategy also optimizes the efficiency and operating life of the diesel generator. Simulation and experimental validation is carried out for a system with $10 \mathrm{~kW}$ PV generation, a $5 \mathrm{kVA}$ battery inverter, a $5 \mathrm{kVA}$ diesel generator and a $5 \mathrm{kVA}$ load.

Keywords: Battery, charge controller, diesel generator, energy management strategy, hybrid system, photovoltaic power, stand-alone system. 


\section{INTRODUCTION}

For remote locations with difficult access to the power grid, stand-alone systems are more cost effective. In fact, these systems are widely established in hilly regions and remote villages where they are used for a wide range of applications such as rural electrification, auxiliary power units for emergency services or military applications, and manufacturing facilities using sensitive electronics [1], [2].

A diesel generator has been traditionally used in stand-alone systems since it greatly reduces the Loss of Load Probability (LOLP) and the initial investment. However, thanks to the PV cost reduction, the addition of photovoltaic generation to a pure diesel system is becoming favorable. The fact that the solar resource is free helps reduce the cost of energy and fuel consumption and to avoid carbon dioxide emissions.

Given the similarities between this stand-alone system and the conventional electric grid, similar approaches could be envisaged for the energy management. Comprehensive reviews on load-frequency control for conventional grids, also including renewable-energy sources, can be found on [3] and [4]. Some conventional approaches include phase shift methods [5], [6], and proportional-integral control [7]. Many authors show that photovoltaic systems can also contribute to the grid stability by providing primary frequency regulation [8]-[10]. In [11], an energy management is developed for a stand-alone system. The photovoltaic inverter follows load variations by means of a fuzzy control which requires irradiance and frequency deviation as inputs. Thanks to the control, frequency deviation is reduced at the expense of limiting the photovoltaic power. In all these cases, the regulation contributes to the energy management because the systems are based on synchronous generators and therefore have an associated inertia. However, energy management in non-inertial systems is considerably different from synchronous-generator-based systems.

A battery energy storage system could also be considered, leading to a hybrid PV-battery-diesel system. Adding a battery makes it possible to integrate a higher photovoltaic power and, at the same time, to reduce frequency deviations. In this case, the diesel generator is usually disconnected, which leads to a non-inertial system based on electronic converters. The hybrid solution is an extremely interesting option, since it achieves a tradeoff between total cost and reliability [12]-[16]. The diesel generator duty cycle is reduced, resulting in increased life and lower maintenance [12], [17]. Furthermore, whenever the diesel generator is used, it can be forced to operate close to its nominal power, for high efficiency [17], [18]. Due to these advantages, photovoltaic generation with battery storage is being added in existing diesel installations whilst new hybrid stand-alone systems are also being installed [14], [15], [19].

The hybrid PV-battery-diesel system requires high-quality energy management for optimal operation. The diesel generator generally remains unconnected, whilst the PV arrays operate under MPPT and the battery offsets the difference between consumption and generation. As a result, the battery State of Charge (SOC) changes accordingly. Then, when the SOC is low, the diesel generator comes into operation. This prevents the battery from an over-discharge and increases the stored energy. On the contrary, when the battery is fully charged and generation is higher than consumption, then the photovoltaic power should be limited in order to protect the battery from overcharging [20], [21].

The type of energy management implemented depends on the system configuration. Two alternatives are generally used depending on the location of the photovoltaic generators, as shown in Fig. 1. In both of them, the diesel generator, loads and battery, through an inverter in that case, are connected to the common AC bus. However, in the first case, the PV arrays are connected to the battery through a $\mathrm{DC} / \mathrm{DC}$ converter whereas in the second case, they are connected to the $\mathrm{AC}$ bus through an inverter.

Due to its simplicity, the first configuration (Fig. 1(a)) is advantageous in many situations. Since the generation and storage are centralized, all the information passes through the control supervisor and a simple energy management strategy can be implemented. When the battery is 
fully charged, the DC/DC converter can easily control the DC bus voltage with no need for communication cables [22]-[27]. However, this structure makes it necessary to install the PV generators close to the battery, which can be a limitation in applications where distributed PV generation is adequate. In these cases, the second configuration becomes more attractive.

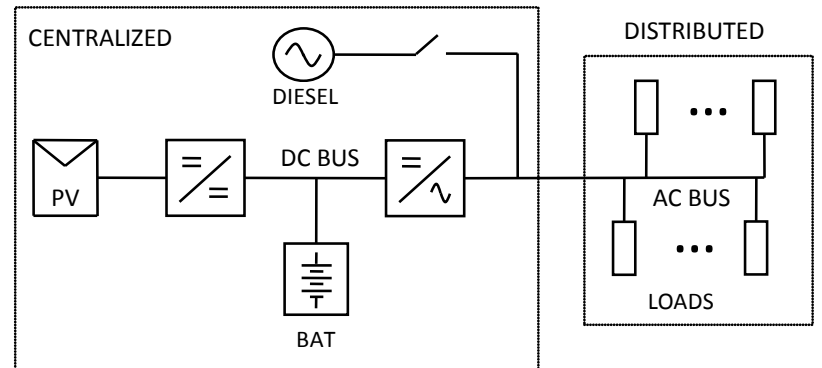

(a) Centralized PV generation

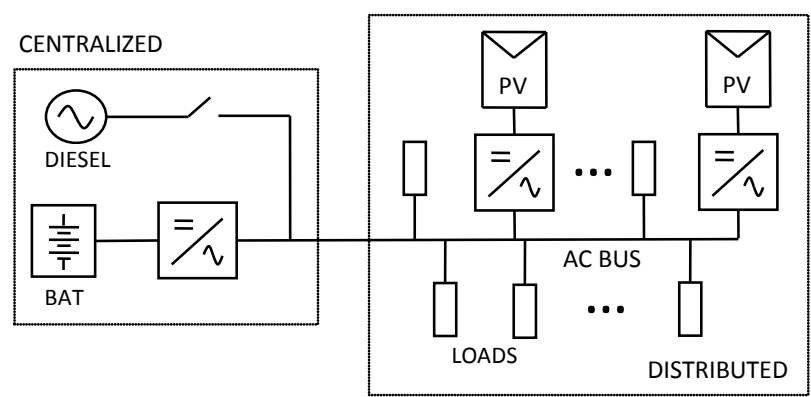

(b) Distributed PV generation

Fig. 1. Stand-alone hybrid system: centralized/distributed PV generation.

The second configuration (Fig. 1(b)) makes it possible to locate the PV arrays near to the loads. It can be convenient in many applications such as rural electrification since the PV arrays can be placed on the house roof and connected directly to the mains [28]-[30]. In normal operation, the diesel generator is not connected. In this situation, the PV inverters operate as current-source inverters (CSI), delivering maximum power. The battery inverter operates as a voltage-source inverter (VSI), setting the grid frequency and voltage [31]. As a result, the battery inverter automatically supplies the required real and reactive power. However, the inconvenience of this system is that communication cables are required in order to reduce the PV power when the battery is fully charged, which makes the system more complex, more expensive and less reliable [32]. Well-known droop methods succeed in sharing the power among parallel VSIs without the need of communication cables [33], [34]. However, the PV power reduction in such a system with no communications has not yet been addressed.

This paper proposes an energy management strategy for the whole system. The strategy makes it possible to limit the distributed PV generation without the need for communication cables. When the battery is fully charged or the battery power exceeds its nominal value, the battery inverter transmits the information through the AC lines by means of a frequency increase. This message is detected by the PV inverters, which continuously reduce the power generated in order to regulate the battery voltage or power, preventing an overcharge or over-current. On the one hand, in doing so, the battery charge is optimized, increasing the battery life whilst, on the other hand, the battery is protected from over-current, making it possible to install a PV peak power higher than the battery inverter rated power, which is often required by the system sizing. This strategy also optimizes the diesel generator operation since it is only connected when there is a low SOC and operates at a high power, thereby increasing its efficiency and expected life. 


\section{SYSTEM DESCRIPTION}

\subsection{Sizing of the elements}

The rated values of the system with distributed PV generation are shown in Fig. 2, where $C_{b a t}$ is the battery rated capacity, $S_{\text {bat, nom }}$ is the battery inverter rated power, $S_{\text {diesel,nom }}$ is the diesel generator rated power, $S_{\text {load,nom }}$ is the load rated power, and $P_{p v, n o m}$ is the total PV inverter rated power.

For a certain application, $S_{\text {load,nom }}$ is given. The battery should at least be able to feed the loads even in the worst case scenario, i.e. with maximum consumption and no generation. It is thus advisable that $S_{\text {bat, nom }} \geq S_{\text {load,nom. }}$

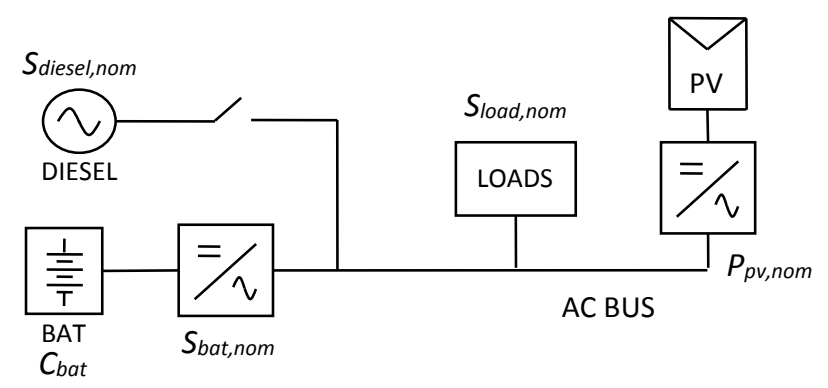

Fig. 2. Sizing of the distributed PV generation system

The PV power sizing strongly depends on the generation and consumption power profiles and therefore on the application and system location. In many cases, the most cost-effective PV power is higher than the load rated power. In principle, this would make it necessary to increase the battery inverter power over $P_{p v, n o m}$ in order to provide system overcurrent protection whenever generation is high and there is no load. However, these systems always require a reduction in the PV power in order to protect the battery from overcharging when it is fully charged. This power limitation can also be used to reduce the size of the battery inverter with regard to the PV inverters, that is $S_{b a t, n o m}<P_{p v, n o m}$. Then, the power absorbed by the battery inverter can reach $P_{p v, n o m}$ during a short transient until the PV power has been reduced. This condition restricts the minimum size of the battery inverter. This paper considers that the battery inverter can withstand twice its rated power for a very short transient (about one second) and thus it must be guaranteed that $S_{b a t, n o m} \geq P_{p v, n o m} / 2$. Finally, the two restrictions for the battery inverter are $S_{b a t, n o m} \geq P_{p v, n o m} / 2$ and $S_{b a t, n o m} \geq S_{\text {load,nom. }}$

Regarding the diesel generator, it should be sized so that $S_{\text {diesel,nom }} \geq S_{\text {load,nom }}$. This guarantees that, when the SOC is low and there is no PV generation, the diesel can completely cover the load demand [12].

The rated values of the system used throughout this paper for the simulation and experimental results, in accordance with the aforementioned sizing, are shown in Table 1.

\begin{tabular}{|c|c|}
\hline$S_{\text {load,nom }}$ & $5000 \mathrm{VA}$ \\
\hline$S_{\text {bat,nom }}$ & $5000 \mathrm{VA}$ \\
\hline$S_{\text {diesel,nom }}$ & $5000 \mathrm{VA}$ \\
\hline$P_{p v, n o m}$ & $5000 \mathrm{~W}$ \\
\hline$P_{p v, \text { nom } 2}$ & $5000 \mathrm{~W}$ \\
\hline$C_{\text {bat }}(10 \mathrm{~h})$ & $240 \mathrm{Ah}$ \\
\hline$V_{\text {bat, nom }}$ & $120 \mathrm{~V}$ \\
\hline
\end{tabular}

Table 1. Rated values of the stand-alone system. 


\subsection{System presentation}

The hybrid stand-alone system is shown in Fig. 3, where $v_{b a t}$ is the battery voltage, $i_{b a t}$ the battery current, $v_{\text {grid }}$ the grid voltage, $i_{i n v}$ the battery inverter current, $v_{\text {diesel }}$ the diesel voltage, $i_{\text {diesel }}$ the diesel current, $i_{p v}$ the total PV inverter current, $i_{L}$ the total load current, $P_{b a t}$ and $Q_{b a t}$ the real and reactive power absorbed by the battery inverter, $P_{\text {diesel }}$ and $Q_{\text {diesel }}$ the real and reactive power supplied by the diesel generator, $P_{L}$ and $Q_{L}$ the real and reactive power demanded by the loads, and $P_{p v}$ the power generated by the PV arrays. The PV inverters do not provide reactive power and power losses are neglected for the analysis. The supervisor is located in the battery inverter and directly measures $v_{\text {bat }}, i_{b a t}, v_{\text {grid }}, i_{\text {inv }}, v_{\text {diesel }}$ and $i_{\text {diesel }}$. From these variables, the difference between the load and PV currents can be obtained as:

$$
i_{L}-i_{p v}=i_{\text {diesel }}-i_{i n v}
$$

However, due to the system configuration and the lack of communication cables, it is not possible to distinguish between $i_{L}$ and $i_{p v}$. The SOC of the battery is also determined by means of:

$$
S O C=S O C_{0}+\frac{\int i_{b a t} \cdot \eta_{b a t} d t}{C_{b a t}}
$$

where $\eta_{\text {bat }}$ is the battery efficiency.

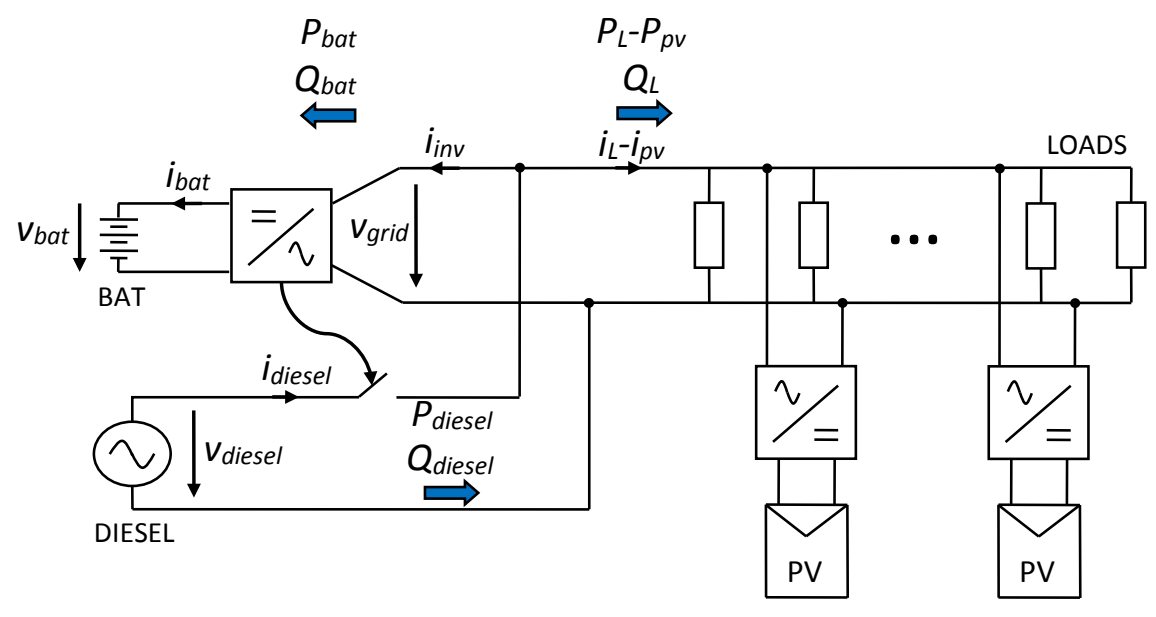

Fig. 3. Voltages, currents and powers known by the supervisor.

\section{PV POWER LIMITATION}

\subsection{PV power limitation description}

There are two situations in which it is necessary to limit the photovoltaic power.

The first one is related to the battery overcharge. When the battery is charged and cannot absorb more power, its voltage will exceed the maximum voltage, $v_{b a t, \max }$. The PV power must then be reduced in order to limit the battery voltage to $v_{b a t, \max }$. The value of voltage $v_{b a t, \max }$ depends on the battery type and charging method. For lead-acid batteries, Three Stage Charging is the most suitable charging algorithm, whereby $v_{b a t, \max }$ is the absorption voltage $v_{b a t, a b s}$ during normal operation and absorption charging and then the float voltage $v_{\text {bat } f l}$ during float charging [35], [36]. For lithium-ion batteries, $v_{\text {bat, } \max }$ is the overcharge voltage [37].

The second situation is related to over-current protection. When the current or power absorbed is too high, the battery current $i_{b a t}$ will exceed the maximum current $i_{\text {bat,max }}$. In this situation, the current must be limited to $i_{b a t, \max }$, which is also achieved thanks to the PV power reduction. The value of $i_{\text {bat,max }}$ depends on two restrictions. It must first be guaranteed that the battery inverter 
RMS current does not exceed its nominal value or, in other words, that the inverter apparent power does not exceed $S_{\text {bat,nom }}$. This can occur even for a low battery power if the battery inverter is feeding high reactive loads. In order to avoid this, $i_{\text {bat, } \max }$ is set to $i_{\text {bat,Smax }}$, which is calculated as follows:

$$
i_{b a t, S \max }=\frac{S_{b a t, n o m} \cdot \cos \varphi}{v_{b a t, m}}
$$

where $\varphi$ is the angle between $v_{\text {grid }}$ and $i_{i n v}$ and $v_{b a t, m}$ is the measured battery voltage.

Secondly, it is also necessary to protect the battery from currents over its maximum allowable current, $i_{\text {bat,Imax }}$. In this way, $i_{\text {bat, } \max }$ will be selected as the minimum value between $i_{\text {bat,Imax }}$ and $i_{\text {bat,Smax }}$. However, in order to make the analysis clearer, the $i_{\text {bat,Smax }}$ is considered to be more restrictive hereafter, making it possible not to account for $i_{\text {bat, Imax }}$.

This paper proposes a technique for reducing the PV power without the need for communication cables. Since the frequency is the same at all the points of the grid, this variable can be used to transmit the information through the AC lines. When a PV power limitation is necessary, the battery inverter increases the frequency. Then, the PV inverters detect the frequency increase and reduce their generated power in order to set the voltage to $v_{b a t, \max }$ or the current to $i_{\text {bat, } \max }$.

The grid frequency is $f=f_{0}+\Delta f$, where $f_{0}$ is the nominal frequency (typically $50 / 60 \mathrm{~Hz}$ ) and $\Delta f$ is the deviation in relation to the nominal value. Figure 4 shows how the frequency deviation $\Delta f$ is obtained. Both frequency deviations $\Delta f_{v}$ and $\Delta f_{i}$, defined in the figure, are calculated to meet the voltage and current limitations, respectively. On the one hand, the difference between the measured battery voltage, $v_{b a t, m}$, and the reference battery voltage $v_{b a t, \max }$ is entered in the controller $\mathrm{C}_{\mathrm{v}}$, which calculates $\Delta f_{v}$, limited from 0 to $\Delta f_{\max }$. On the other hand, from the difference between the measured battery current, $i_{\text {bat } m}$, and the reference battery current $i_{\text {bat,max }}$, the controller $C_{\mathrm{i}}$ determines $\Delta f_{i}$, also limited from 0 to $\Delta f_{\max }$. Then, the highest value $\Delta f$ is selected since it is more restrictive and the battery inverter imposes the frequency $f_{0}+\Delta f$.

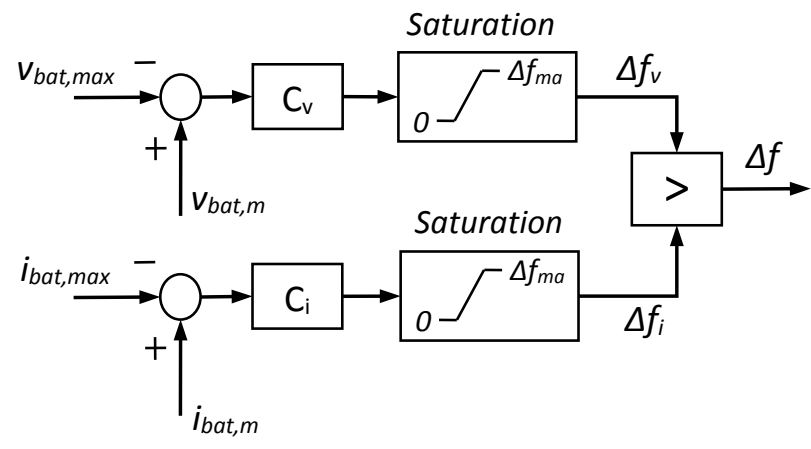

Fig. 4. Calculation of $\Delta f$.

In operation, the battery inverter imposes a constant RMS value $V_{0}$ and a frequency $f=f_{0}+\Delta f$. Thus, $v_{\text {grid }}$ can be expressed as:

$$
v_{\text {grid }}=\sqrt{2} V_{0} \cdot \sin \left(2 \pi\left(f_{0}+\Delta f\right) \cdot t\right)
$$

Each PV inverter measures the frequency and obtains the measured frequency deviation $\Delta f_{m}$. The frequency measurement does not involve an additional cost since this is already included in PV inverters for anti-islanding detection. The microprocessor makes this measurement by detecting the period between two zero crossings of the grid voltage. The frequency is then highly filtered in order to avoid noise, transients and external interferences. If $\Delta f_{m}$ is higher than a minimum safe value $\Delta f_{\min }$, then the PV inverter stores the MPP power, to be called $P_{m p p, f r}$, and continuously reduces the power generated up to a frequency deviation $\Delta f_{\max }$, where the power is 
zero. Since the value of $P_{m p p, f r}$ is taken instead of $P_{p v, n o m}$, the PV power starts to be reduced just when $\Delta f_{m}>\Delta f_{\min }$, resulting in a faster control. The frequency sensing $\mathrm{H}_{\mathrm{f}}$ and the relationship between the frequency deviation and the reference PV power $P_{p v}^{*}$ are shown in Fig. 5.

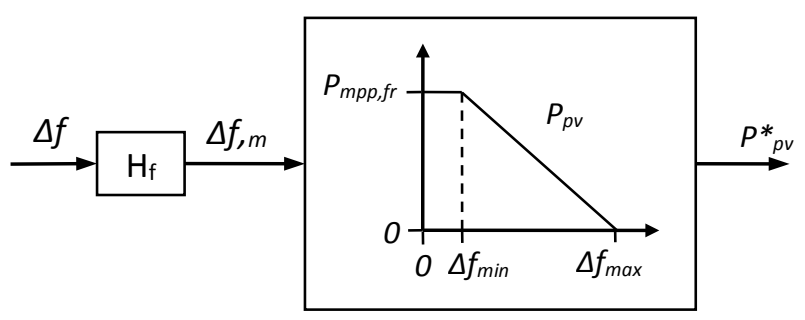

Fig. 5. Calculation of PV power reference $P^{*}{ }_{p v}$.

In order to carry out the PV power regulation, the first stage of the PV inverter, which is a $\mathrm{DC} / \mathrm{DC}$ boost converter, is controlled as shown in Fig. 6 . When $\Delta f_{m}$ gets higher than $\Delta f_{\min }$, the MPPT algorithm is cancelled and the PV voltage reference is frozen to its last value, $v_{m p p, f r}$. The PV voltage is regulated by means of a PI controller [38]. On the other hand, the power reference $P_{p v}^{*}$ is divided by the measured PV voltage $v_{p v, m}$. Then, the lowest value is selected as the current reference for the inner current control. In so doing, when $\Delta f_{m}>\Delta f_{\min }$, the power regulation is active, with $v_{p v}>v_{m p p}$. However, there are situations in which the power reference can no longer be delivered, for example after an irradiance drop. In these cases, the PV voltage decreases and the control switches to voltage regulation, which prevents a PV voltage drop in the system. The voltage control is maintained until $\Delta f_{m}$ gets lower than $\Delta f_{\min }$ and the MPPT is then performed. More details about this technique are shown in [39].

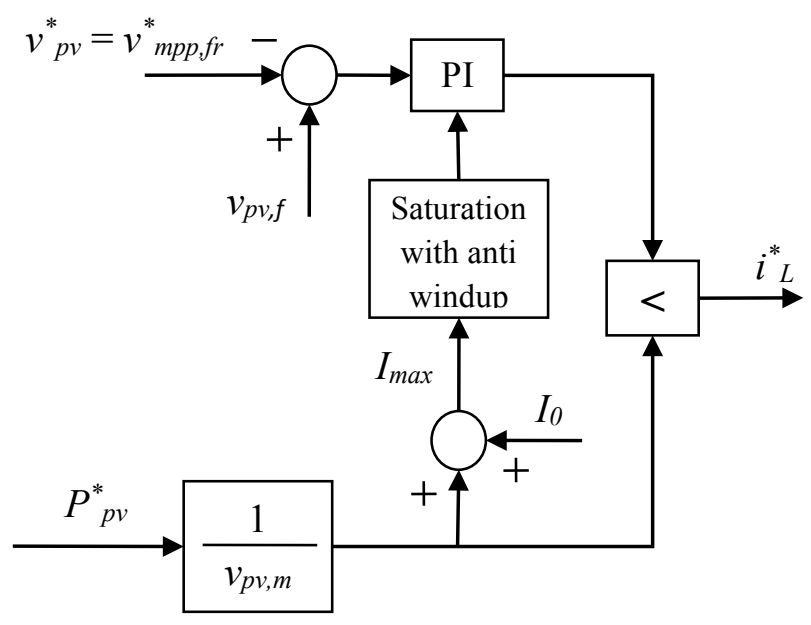

Fig. 6. PV power regulation in the PV boost converter.

Normally, $v_{b a t}$ is lower than $v_{b a t, \max }$ and $i_{b a t}$ is lower than $i_{b a t, \max }$. As a result, $\Delta f_{v}$ and $\Delta f_{i}$ remain saturated to zero, the grid frequency is $f_{0}$ and the PV generators operate under MPPT (see Fig. 4 and Fig. 5). Then, when the battery is charged and its voltage exceeds $v_{b a t, \max }$, the controller $\mathrm{C}_{\mathrm{v}}$ increases $\Delta f_{v}$ and the battery inverter increases the grid frequency. When $\Delta f_{v}>\Delta f_{\min }$, the PV inverter reduces the power generated and regulates the battery voltage. Similarly, when the apparent power of the battery inverter is higher than its nominal value, then $i_{\text {bat }}>i_{\text {bat } \max }$. The controller $\mathrm{C}_{\mathrm{i}}$ increases the frequency and the PV generation is reduced, limiting the battery inverter current. 


\subsection{System modeling}

The speed and stability of the battery voltage and current controls depend on the system and controller features. In order to correctly calculate the controller parameters, a model of the system is carried out in this section. The loops for the battery voltage and current regulations are shown in Fig. 7 and Fig. 8, respectively. The different blocks are presented below.

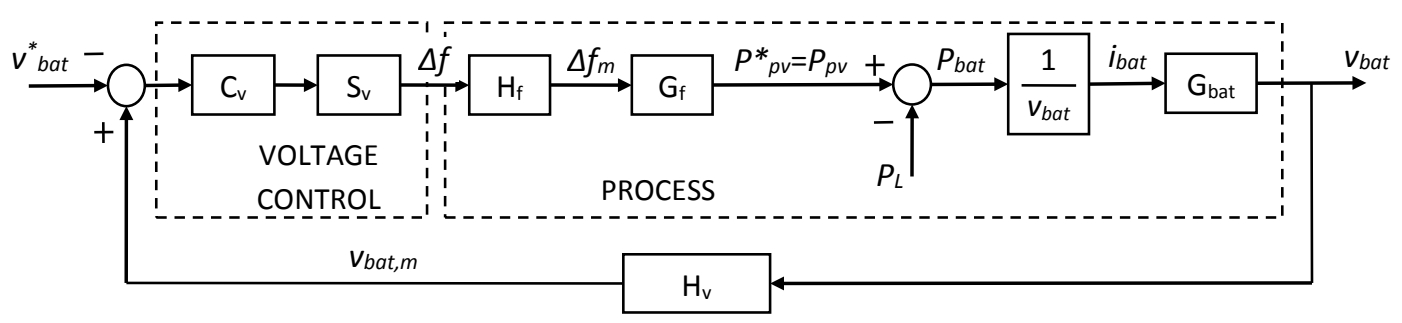

Fig. 7. Battery voltage control loop.

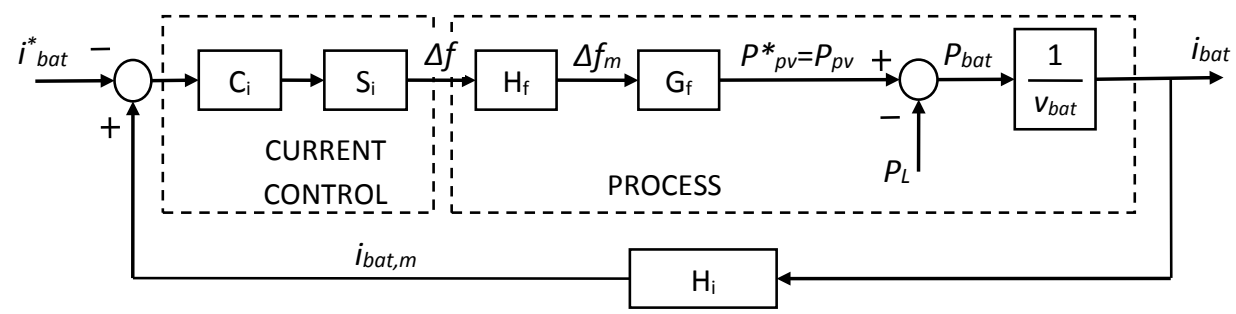

Fig. 8. Battery current control loop.

The sensing transfer function for the battery voltage $v_{\text {bat }}\left(\mathrm{H}_{\mathrm{v}}\right)$, the battery current $i_{\text {bat }}\left(\mathrm{H}_{\mathrm{i}}\right)$ and frequency $f\left(\mathrm{H}_{\mathrm{f}}\right)$ can be considered as a first order:

$$
\begin{aligned}
& H_{v}(s)=\frac{1}{\tau_{v} \cdot s+1} \\
& H_{i}(s)=\frac{1}{\tau_{i} \cdot s+1} \\
& H_{f}(s)=\frac{1}{\tau_{f} \cdot s+1}
\end{aligned}
$$

where $\tau_{v}$ is the time constant of the battery voltage sensing, $\tau_{i}$ is the time constant of the current voltage sensing and $\tau_{f}$ is the time constant of the frequency sensing.

Controllers $\mathrm{C}_{\mathrm{v}}$ and $\mathrm{C}_{\mathrm{i}}$ are Proportional-Integral (PI) regulators with parameters $K_{p v}, T_{n v}, K_{p i}, T_{n i}$. Their transfer functions are:

$$
\begin{aligned}
& C_{v}(s)=K_{p v} \frac{T_{n v} \cdot s+1}{T_{n v} \cdot s} \\
& C_{i}(s)=K_{p i} \frac{T_{n i} \cdot s+1}{T_{n i} \cdot s}
\end{aligned}
$$

Since the controllers used for the implementation are digital, a digital sampler $S_{\mathrm{v}}$ and $\mathrm{S}_{\mathrm{i}}$ must be added to the model. Being $T_{S}$ the sample time, they can be approximated as [40]:

$$
S_{v}(s)=S_{i}(s)=\frac{1}{1.5 \cdot T_{s} \cdot s+1}
$$

The relationship between the frequency deviation $\Delta f$ and the reference PV power $P^{*}{ }_{p v}$ for $\Delta f>\Delta f_{\min }$ is expressed as (see Fig. 5): 


$$
P_{p v}^{*}=\frac{\Delta f_{\max }-\Delta f}{\Delta f_{\max }-\Delta f_{\min }} \cdot P_{m p p, f r}
$$

By means of (11) and small-signal modeling (small-signal variables are marked with a hat), the frequency deviation to power reference transfer function $\mathrm{G}_{\mathrm{f}}$ becomes:

$$
G_{f}=\frac{\hat{P}_{p v}^{*}(s)}{\Delta \widehat{f}(s)}=-\frac{P_{m p p, f r}}{\Delta f_{\max }-\Delta f_{\min }}
$$

The PV power regulation is carried out by means of the technique developed in [39], presented in Fig. 6. This technique achieves high dynamics for the power regulation and it can thus be considered that $P_{p v}=P^{*}{ }_{p v}$ for the outer loop.

Neglecting power losses, battery power $P_{b a t}$ and $i_{b a t}$ can be obtained as:

$$
\begin{aligned}
& P_{b a t}=P_{p v}-P_{L} \\
& i_{b a t}=\frac{P_{b a t}}{v_{b a t}}
\end{aligned}
$$

Finally, considering the small-signal analysis of the Thevenin lead-acid battery equivalent circuit model, the battery current to voltage transfer function $\mathrm{G}_{\mathrm{bat}}$ can be obtained as [25]:

$$
G_{b a t}(s)=\frac{\hat{v}_{b a t}(s)}{\hat{i}_{b a t}(s)}=\frac{\left(R_{1}+R_{2}\right)+R_{1} \cdot R_{2} C \cdot s}{1+R_{2} C \cdot s}
$$

where $R_{1}$ is the internal resistance and $R_{2}$ and $C$ represent the first order dynamics of the battery. These parameters can be considered constant for modeling purposes since the SOC slightly changes within the operating range of the voltage regulation.

\subsection{Controller design}

The controller parameters are obtained by means of the aforementioned modeling, which is summarized in Fig. 7 and Fig. 8. In our system, the parameters are $\tau_{f}=1 \mathrm{~s}, T_{s}=100 \mathrm{~ms}$, $\Delta f_{\min }=0.2 \mathrm{~Hz}, \Delta f_{\max }=1 \mathrm{~Hz}, R_{1}=50 \mathrm{~m} \Omega, R_{2}=12 \mathrm{~m} \Omega, C=1.5 \mathrm{~F}, v_{b a t, \max }=147 \mathrm{~V}$. Voltage and current sensing transfer functions can be neglected since $1 / \tau_{v}=1 / \tau_{i}=13500 \mathrm{rad} / \mathrm{s}$ is much higher than the cutoff frequency. For both voltage and current loops, $P_{m p p, f r}$ is first taken as $P_{p v, n o m} / 2=5 \mathrm{~kW}$ for the controller parameter calculation. However, $P_{m p p, f r}$ largely depends on the irradiance and it can vary up to $P_{p v, n o m}=10 \mathrm{~kW}$ in this case (see Table 1). Thus, a robustness analysis is carried out for other values of $P_{m p p, f r}$.

For the voltage control loop, the operating battery voltage is very close to $v_{b a t \text {, } m a x}$ and thus it can be considered that $v_{b a t}=v_{b a t, m a x}$. The values of $K_{p v}$ and $T_{n v}$ are calculated for a cutoff frequency $f_{c v}=0.2 \mathrm{~Hz}$ and a phase margin $P M_{v}=60^{\circ}$. However, when a parameter differs from the parameter considered in the model, the cutoff frequency and phase margin are not equal to $0.2 \mathrm{~Hz}$ and $60^{\circ}$. For this reason, the cutoff frequency $f_{c v}$ and the phase margin $P M_{v}$ have been obtained for different values of $P_{m p p, f r}$, from 1 to $10 \mathrm{~kW}$, and are represented in Fig. 9. It can be observed that the regulation is always stable with a minimum $P M_{v}=54.4^{\circ}$ for $P_{m p p, f r}=10 \mathrm{~kW}$. The figure also shows that the regulation becomes slower for low values of $P_{m p p, f r}$, which does not represent a problem since the over-voltage is less important for low $P_{m p p, f r}$.

For the current control, the operating battery voltage is around nominal voltage and thus it can be considered that $v_{b a t}=v_{b a t, n o m}$. Current control parameters $K_{p i}$ and $T_{n i}$ are obtained for a cutoff frequency $f_{c i}=0.3 \mathrm{~Hz}$ and a phase margin $P M_{i}=60^{\circ}$. Similarly to the voltage control loop, the cutoff frequency $f_{c i}$ and phase margin $P M_{i}$ are depicted in Fig. 10 as a function of $P_{m p p, f r}$. The regulation is also stable in this case, with a minimum $P M_{v}=53.6^{\circ}$ for $P_{m p p, f r}=10 \mathrm{~kW}$. The cutoff frequency increases for high $P_{m p p, f r}$, which protects the battery converter from dangerous over-currents. 

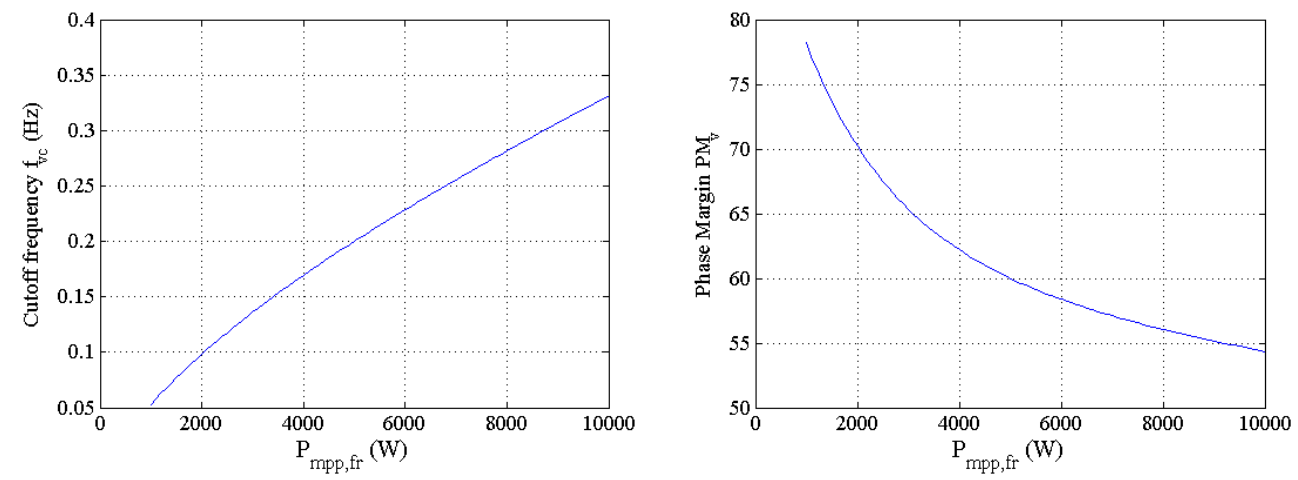

Fig. 9. Cutoff frequency and phase margin of the voltage control for different values of $P_{m p p, f r}$.
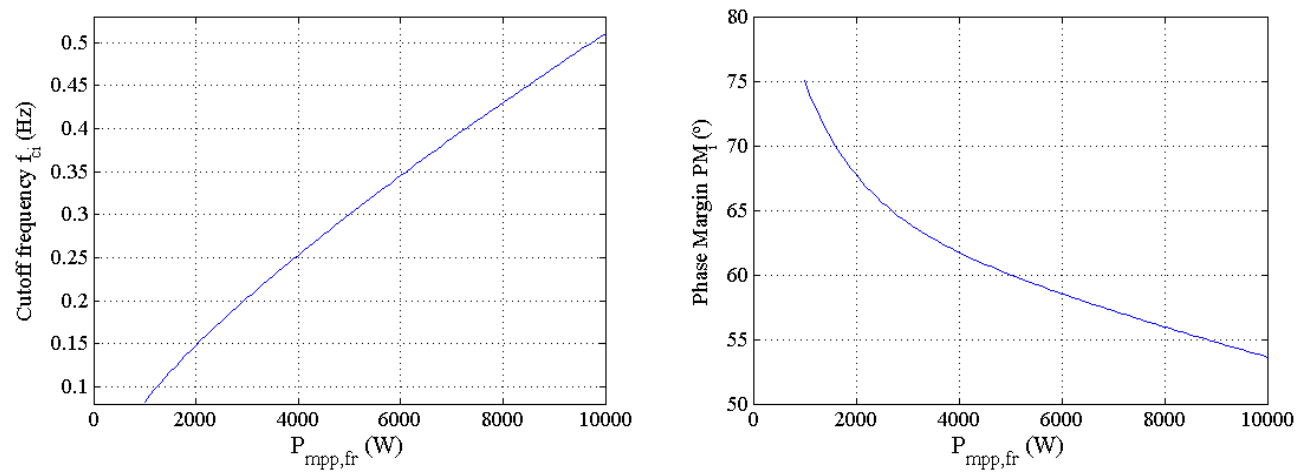

Fig. 10. Cutoff frequency and phase margin of the current control for different values of $P_{m p p, f r}$.

\section{PROPOSED ENERGY MANAGEMENT STRATEGY}

The proposed energy management strategy consists of three modes of operation. The behavior of each element of the system in each mode of operation as well as the conditions required to switch from one mode to another are represented in Fig. 11.

\begin{tabular}{|c|c|c|c|}
\hline Mode of operation & Battery inverter & PV inverters & Diesel \\
\hline $\begin{array}{c}\text { Mode I: Normal } \\
\text { operation }\end{array}$ & $\begin{array}{c}\text { Voltage source } \\
\Delta f<\Delta f_{\min }\end{array}$ & MPPT & Off \\
\hline $\begin{array}{c}\text { Mode II: PV } \\
\text { power limitation }\end{array}$ & $\begin{array}{c}\text { Voltage source } \\
\Delta f>\Delta f_{\min }\end{array}$ & $\begin{array}{c}\text { Power } \\
\text { limitation }\end{array}$ & Off \\
\hline $\begin{array}{c}\text { Mode III: } \\
\text { Diesel generator }\end{array}$ & $\begin{array}{c}\text { Current source } \\
P_{b a t}=\min \left(P_{\text {avaiilable }}, S_{\text {bat }, \text { nom }}\right)\end{array}$ & MPPT & $\begin{array}{c}\text { On } \\
f \approx f_{0}\end{array}$ \\
\hline
\end{tabular}

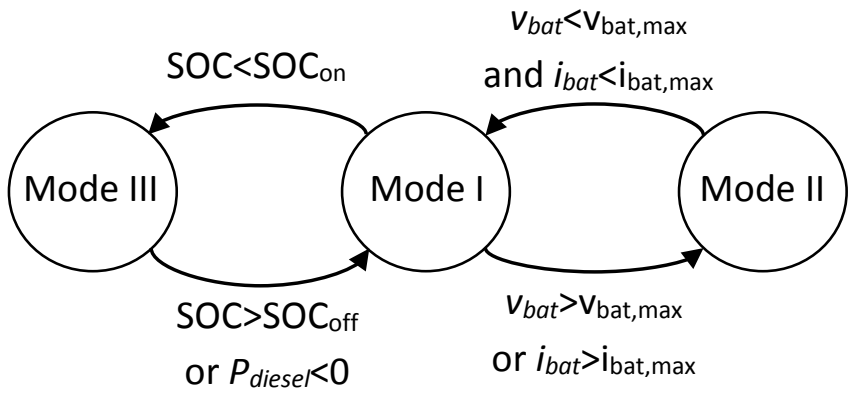

Fig. 11. Mode of operation and change conditions 


\subsection{Mode I: normal operation}

In mode I, the diesel generator is not connected, the PV inverters operate under MPPT and the battery inverter creates the grid. As a result, the battery absorbs or supplies the difference between generation and consumption and its SOC varies according to (2). The power balance becomes:

$$
\begin{aligned}
& P_{b a t}=P_{p v}-P_{L} \\
& Q_{b a t}=-Q_{L}
\end{aligned}
$$

In this mode, the frequency deviation $\Delta f$ is zero or lower than $\Delta f_{\min }$. When due to a high battery voltage or current, the regulation increases $\Delta f$ to more than $\Delta f_{\min }$ (see Fig. 4 and Fig. 5), then the PV inverters reduce their power and the system switches to mode II. On the other hand, if the $\mathrm{SOC}$ falls below $\mathrm{SOC}_{\mathrm{on}}$, then the diesel generator is turned on and, after a synchronization period, the system switches to mode III.

\subsection{Mode II: PV power limitation}

In mode II, the diesel generator is not connected and the battery inverter creates the grid. The grid frequency deviation is higher than $\Delta f_{\min }$ and, as a result, the PV power is lower than its maximum power. The power balance is the same as for mode I. Thanks to the voltage or current control, the frequency and PV power are regulated in order to keep a constant voltage or current, equal to its reference (see Fig. 7 and Fig. 8). When the system is not able to maintain that reference (due to a decrease in irradiance for example), the regulation reduces the frequency below $\Delta f_{\min }$ and the system switches to mode I.

\subsection{Mode III: diesel generator}

In mode III, the diesel generator is connected and creates the grid whereas the battery inverter operates as a current source inverter (CSI) in phase with the grid voltage. The frequency generated by the diesel generator does not need to be just equal to $f_{0}$ but must be lower than $f_{0}+\Delta f_{\min }$. Thus, the PV inverters operate under MPPT. The power balance is as follows:

$$
\begin{aligned}
& P_{\text {diesel }}=P_{b a t}+P_{L}-P_{p v} \\
& Q_{\text {diesel }}=Q_{L}
\end{aligned}
$$

In this situation, the battery power is a degree of freedom. In order to optimize the system operation, the battery inverter demands a power $P_{\text {available, }}$, defined as the power available in the diesel generator once the PV arrays and the loads have been considered:

$$
P_{\text {available }}=\sqrt{S_{\text {diesel, nom }}^{2}-Q_{L}^{2}}+P_{p v}-P_{L}
$$

Since in this mode the battery demands $P_{\text {available, }}$ it can be observed from (18)-(20) that the diesel generator operates at nominal current $\left(S_{\text {diesel }}=S_{\text {diesel,nom }}\right)$. However, if $P_{\text {available }}>S_{\text {bat, nom }}$, the battery cannot absorb $P_{\text {available }}$ and demands $P_{\text {bat }}=S_{\text {bat,nom }}$. Under these circumstances, it is not possible to operate the diesel generator at its nominal current $\left(S_{\text {diesel }}<S_{\text {diesel,nom }}\right)$. Then, by means of (18), the power balance becomes:

$$
P_{\text {diesel }}=S_{\text {bat }, \text { nom }}+P_{L}-P_{p v}
$$

The system will continue in mode III with $P_{b a t}=\min \left(P_{\text {available }}, S_{\text {bat,nom }}\right)$ until the SOC exceeds $\mathrm{SOC}_{\text {off, }}$ the point at which the diesel generator is disconnected and the system switches to mode I. As a result, its efficiency is maximized and its connection time is reduced, increasing its life expectancy.

However, during mode III, if the PV generation increases and the load decreases, the diesel generator could absorb power. From (21), $P_{\text {diesel }}<0$ could occur for: 


$$
P_{p v}-P_{L}>S_{b a t, n o m}
$$

In this situation, in order to prevent the diesel generator from absorbing power and accelerating, it is disconnected and the system therefore switches to mode I. Right away, the battery inverter absorbs a power higher than $S_{\text {bat,nom }}$ (see (16) and (22)). As a result, the battery current regulation makes the battery inverter increase the frequency and the system switches to mode II.

\section{SIMULATION RESULTS}

The proposed energy management strategy was first validated by simulation. Using the PSIM software, an accurate model was developed for all the elements of the system with distributed PV generation. The system is illustrated in Fig. 3, including two PV generators with their inverters. The rated power of the elements is shown in Table 1.

The first simulation was to validate the system operation in mode I and mode II as well as the transition from one mode to another. In these modes the diesel generator was not connected. The results are shown in Fig. 12. The represented variables were $v_{b a t}^{*}=v_{b a t, a b s}=147 \mathrm{~V}$ and $v_{b a t, m}$ (graph 1); $S_{\text {bat,nom }}=5 \mathrm{kVA}$ and $S_{\text {bat }}$ (graph 2); $\Delta f_{i}, \Delta f_{v}$ (note that $\Delta f=\max \left(\Delta f_{v}, \Delta f_{i}\right)$ was imposed by the battery inverter) and the frequency deviation measured by the PV inverters $\Delta f_{, m}$ (graph 3); $P_{b a t}, P_{l o a d}, P_{p v}=P_{p v 1}+P_{p v 2}$ and $P_{m p p}=P_{m p p 1}+P_{m p p 2}$ (graph 4); $Q_{b a t}, Q_{l o a d}$ and the reactive power delivered by the PV inverters $Q_{p v}=Q_{p v 1}+Q_{p v 2}$ (graph 5).

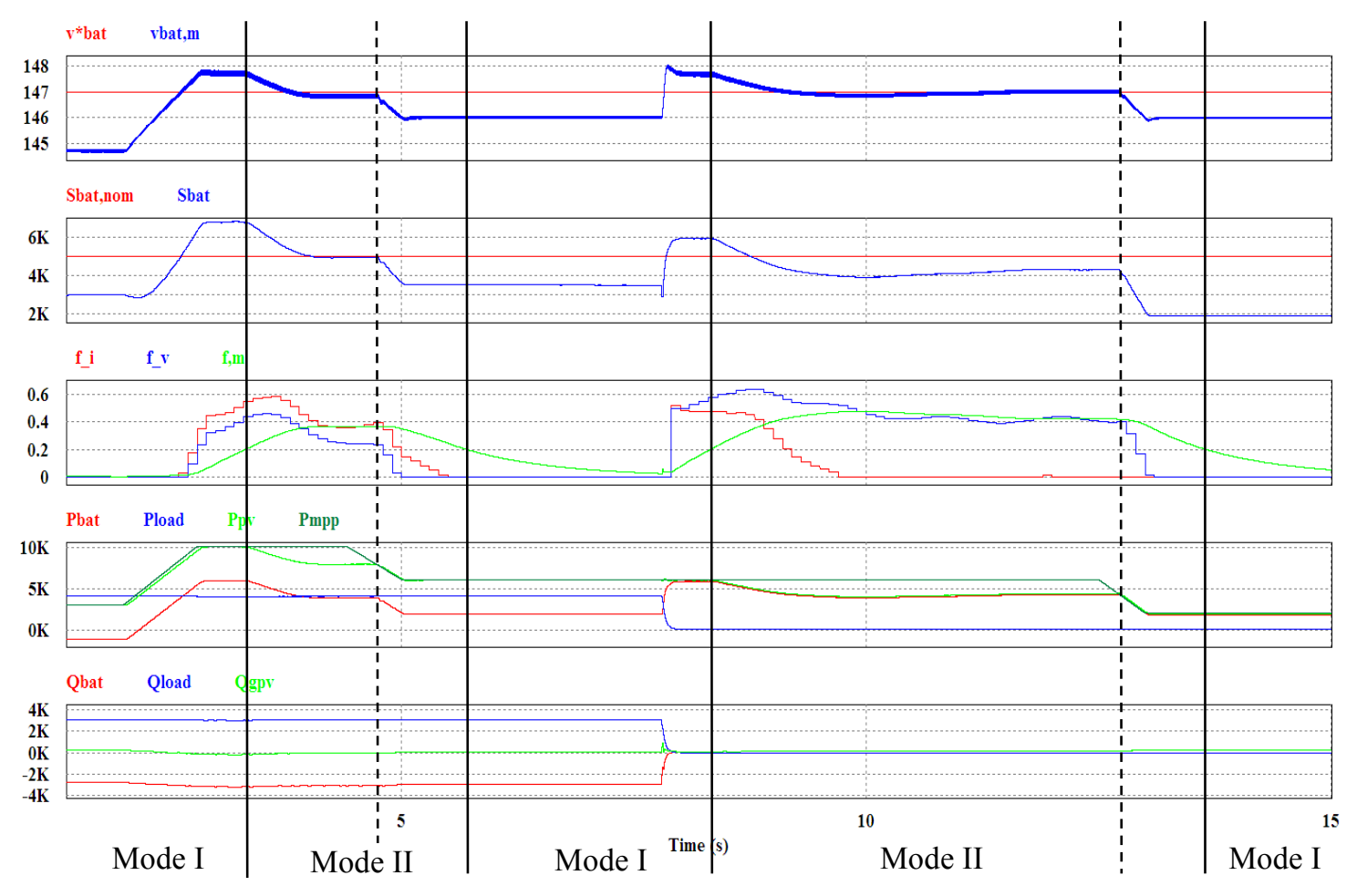

Fig. 12. Simulation results.

At the start, the nominal load was connected, consuming $P_{\text {load }}=4 \mathrm{~kW}$ and $Q_{\text {load }}=3 \mathrm{kVAr}$, and the PV generators operated under MPPT, with $P_{p v}=P_{m p p}=3 \mathrm{~kW}$. Since $v_{b a t, m}<v^{*}$ bat and $S_{\text {bat }}<S_{\text {bat,nom }}$, the frequency deviation $\Delta f$ was saturated at 0 (see Fig. 4 ) and the system remained in mode I. Then, the irradiance increased as did $P_{m p p}$. Initially, the MPPT algorithms maximized the PV power. However, when $v_{b a t, m}$ exceeded $v^{*}{ }_{b a t}$, controller $\mathrm{C}_{\mathrm{v}}$ increased $\Delta f_{v}$ and when $S_{b a t}$ exceeded $S_{\text {bat, nom }}$, controller $\mathrm{C}_{\mathrm{i}}$ increased $\Delta f_{i}$. As a result, the battery inverter selected the highest $\Delta f$ value and increased the frequency. When the frequency filtered by PV inverter $\Delta f_{, m}$ became higher than $\Delta f_{\min }=0.2 \mathrm{~Hz}$, then the PV power was limited following the curve shown in Fig. 5 
and the system switched to mode II. Thanks to the battery current control (see Fig. 8), $S_{\text {bat }}$ was regulated to its nominal power $5 \mathrm{kVA}$, with $P_{b a t}=4 \mathrm{~kW}$ and $Q_{b a t}=-3 \mathrm{kVAr}$. The transient overcurrent had a duration of 1.2 seconds, which did not affect the components. Then, the irradiance and thus $P_{m p p}$ decreased. At the start, the PV power remained at $P_{p v}=8 \mathrm{~kW}$. However, when $P_{m p p}$ fell below $8 \mathrm{~kW}$, this power could not be delivered. The PV voltage was then controlled to the last MPP voltage $v_{m p p, f r}$ in order to avoid a voltage drop (see Fig. 6). In this case, the PV power was close to the MPP power since the MPP voltage had not changed significantly during the power limitation. As a result of the irradiance drop, $S_{\text {bat }}$ fell below $S_{\text {bat, nom }}$ and controller $\mathrm{C}_{\mathrm{i}}$ reduced $\Delta f$. When $\Delta f_{m}$ fell below $0.2 \mathrm{~Hz}$, the PV arrays changed to MPPT and the system switched to mode I. Then, at second 7.8, the whole load was instantly disconnected. At this moment in time, the battery power changed from $P_{b a t}=2 \mathrm{~kW}$ to $P_{b a t}=6 \mathrm{~kW}, Q_{b a t}=3 \mathrm{kVAr}$ to $Q_{b a t}=0$ and $S_{\text {bat }}=3.6 \mathrm{kVA}$ to $S_{\text {bat }}=6 \mathrm{kVA}$ and the battery voltage changed from $146 \mathrm{~V}$ to $148 \mathrm{~V}$. Since there was no reactive power, the voltage condition was now more restrictive and $\Delta f_{v}$ increased to above $\Delta f_{i}$. When $\Delta f_{, m}$ inceased to more than $\Delta f_{\min }=0.2 \mathrm{~Hz}$, the system switched to mode II and the PV power was reduced in such a way that the battery voltage was regulated to absorption voltage. Finally, at second 12.5, the irradiance decreased and the PV voltage was initially controlled. Then, the frequency was reduced, the PV arrays changed to MPPT and the system switched to mode I.

The second simulation was to validate the system operation in mode III as well as the connection and disconnection of the diesel generator. The results are plotted in Fig. 13 for real powers $P_{b a t}, P_{l o a d}, P_{p v}$ and $P_{\text {diesel }}$ (graph 1), reactive powers $Q_{b a t}, Q_{l o a d}, Q_{p v}$ and $Q_{\text {diesel }}$ (graph 2), $S_{\text {bat, nom }}=S_{\text {diesel, nom }}=5 \mathrm{kVA}, S_{\text {bat }}$ and $S_{\text {diesel }}($ graph 3$)$.

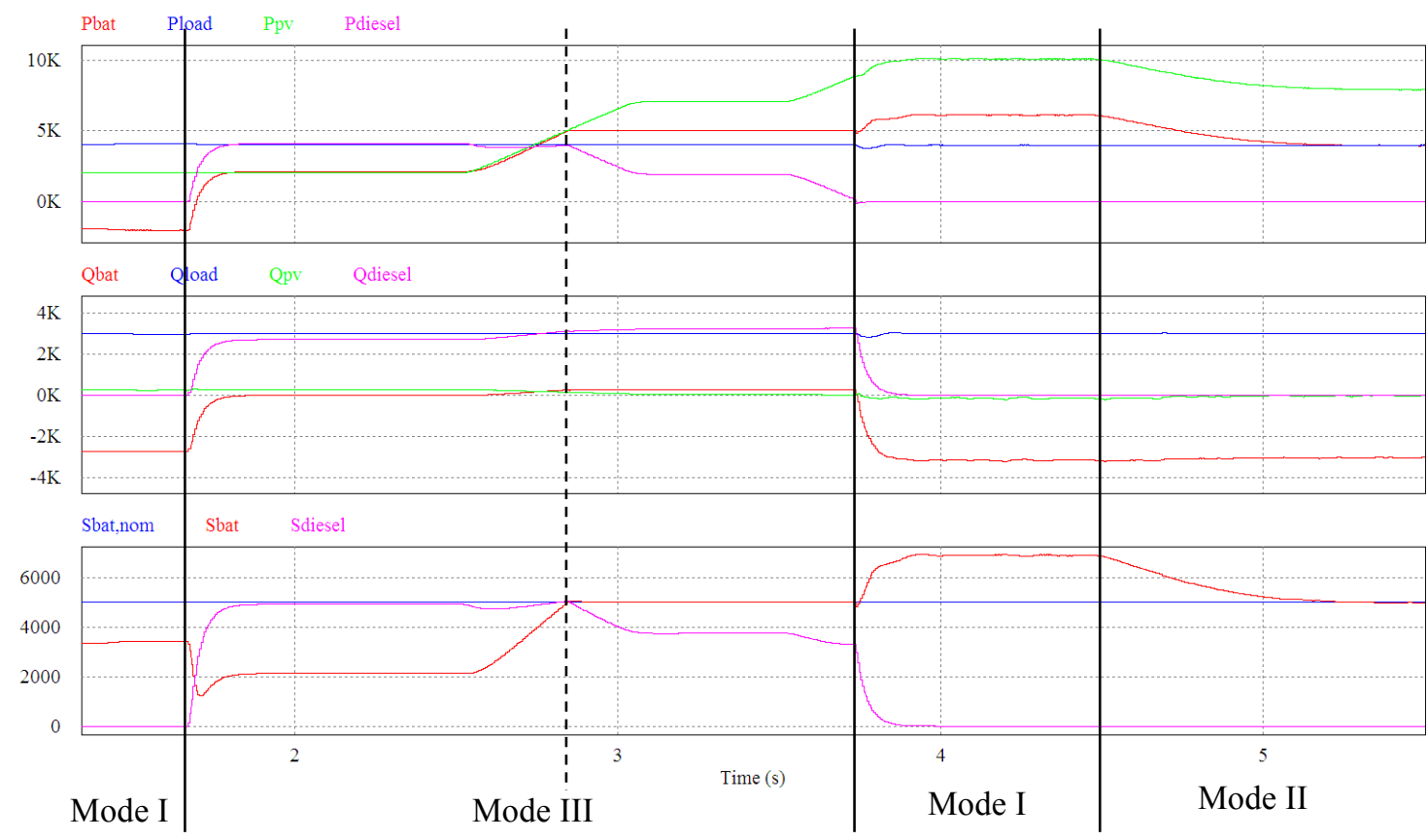

Fig. 13. Simulation results.

The system was initially in mode I. The nominal load was connected and consumed $P_{\text {load }}=4 \mathrm{~kW}$ and $Q_{\text {load }}=3 \mathrm{kVAr}$ while the PV inverters functioned under MPPT with $P_{p v}=$ $2 \mathrm{~kW}$. The diesel generator was not connected and the battery inverter therefore provided the difference between generation and consumption, that is $P_{b a t}=-2 \mathrm{~kW}$ and $Q_{b a t}=-3 \mathrm{kVAr}$. After some time in this mode, the battery $\mathrm{SOC}$ fell below $\mathrm{SOC}_{\text {on. }}$. As a result, the diesel generator was turned on, the battery inverter voltage was synchronized and then, at about second 1.7, the diesel generator was connected, switching to mode III. From that moment onwards, the battery inverter functioned as a current source demanding power $P_{\text {available }}$ (see (20)), which caused the diesel generator to operate at nominal power $S_{\text {diesel }}=S_{\text {diesel, nom }}=5 \mathrm{kVA}$, with $P_{\text {diesel }}=4 \mathrm{~kW}$ and 
$Q_{\text {diesel }}=3 \mathrm{kVAr}$. Then, at second 2.5, the irradiance increased, as did the PV power generation up to $P_{p v}=7 \mathrm{~kW}$. During this PV power increase, at first $S_{\text {diesel }}$ remained equal to $S_{\text {diesel,nom }}$ thanks to a higher $P_{b a t}$ demand. However, when $S_{b a t}$ reached $S_{b a t, n o m}$ at second 2.8, the battery inverter was unable to absorb more power. As a result, $P_{\text {diesel }}$ and $S_{\text {diesel }}$ decreased until the irradiance stopped rising at second 3 , leading to $P_{\text {diesel }}=2 \mathrm{~kW}$ and $S_{\text {diesel }}=3.7 \mathrm{kVA}$. Then, at second 3.5, the irradiance increased again as did the PV power generation up to $P_{p v}=10 \mathrm{~kW}$. At the beginning, since the battery inverter could not demand more power, $P_{\text {diesel }}$ continued decreasing. At second 3.7, $P_{\text {diesel }}$ was very low and, in order to prevent the diesel generator from absorbing power, it was disconnected. The system therefore switched to mode I: the battery inverter controlled the grid voltage and the PV inverters remained under MPPT. Consequently, at the end of the irradiance increase, the battery inverter was overcharged, with $P_{b a t}=6 \mathrm{~kW}$ and $S_{b a t}=6.8 \mathrm{kVA}$. This fact caused controller $\mathrm{C}_{\mathrm{i}}$ to increase the frequency and, at second $4.5, \Delta f_{, m}$ became higher than $\Delta f_{\min }=0.2 \mathrm{~Hz}$, making the system switch to mode II. As a result, the PV power was continuously reduced and $S_{b a t}$ was controlled to $S_{b a t, n o m}$.

\section{EXPERIMENTAL RESULTS}

The proposed energy management strategy was experimentally validated for the system represented in Fig. 3 (for two PV generators with their inverters). The elements used for the experimental setup are shown in Fig. 14, and their rated power is indicated in Table 1. The PV emulators (only one is shown) imitate the behavior of two $5 \mathrm{~kW} \mathrm{PV}$ arrays and make it possible to change the irradiance as required. The battery and PV inverters are commercial inverters whose configuration has been modified in order to implement the proposed strategy. The battery inverter was programmed to increase the grid frequency according to the strategy developed in section 3 and also to manage the diesel generator connection and operation following the strategy presented in section 4 whilst the PV inverters were programmed to reduce the power generated as a function of the grid frequency according to Fig. 5. The load bank made it possible to select the desired power and power factor. The experimental values were taken from the battery and PV inverter microprocessors. The irradiance variations represent quick cloud passages and account for the size of the PV generator. The irradiance variation was not simultaneous for both PV generators, modeling their different locations.

In the first test, the PV power limitation for over-current protection was verified. The test conditions were similar to those of the first part of the first simulation (see section 5, switch from mode I to mode II and back to mode I). The experimental results were taken from the microprocessor and are shown in Fig. 15. Variables $S_{b a t, n o m}=5 \mathrm{kVA}$ and $S_{b a t}$ are represented in the first graph; grid frequency $f_{b a t}$ and grid frequency filtered by the PV inverter, $f_{p v l}$ and $f_{p v 2}$, in the second graph; and $P_{b a t}, P_{p v 1}$ and $P_{p v 2}$, in the third graph. At the start, the system was operating in mode I with the PV inverters under MPPT. However, after an irradiance increase, the battery inverter absorbed an over-current. As a result, the battery inverter increased the grid frequency, which led to a PV power reduction when $f_{p v l}=f_{p v 2}>50.2 \mathrm{~Hz}$. This made it possible to control the battery apparent power to its rated value. Then, due to a fall in irradiance, it was not possible to maintain $S_{\text {bat,nom. }}$. Thus, according to the control of Fig. 4, the frequency fell below $50.2 \mathrm{~Hz}$, the system switched to mode I and the PV inverters once again operated under MPPT. With this test, it can be observed that the current control is fast enough to protect the battery inverter. Indeed, after a quick irradiance increase, the transient over-current lasts for about one second, which does not pose an overheating hazard for the inverter. 


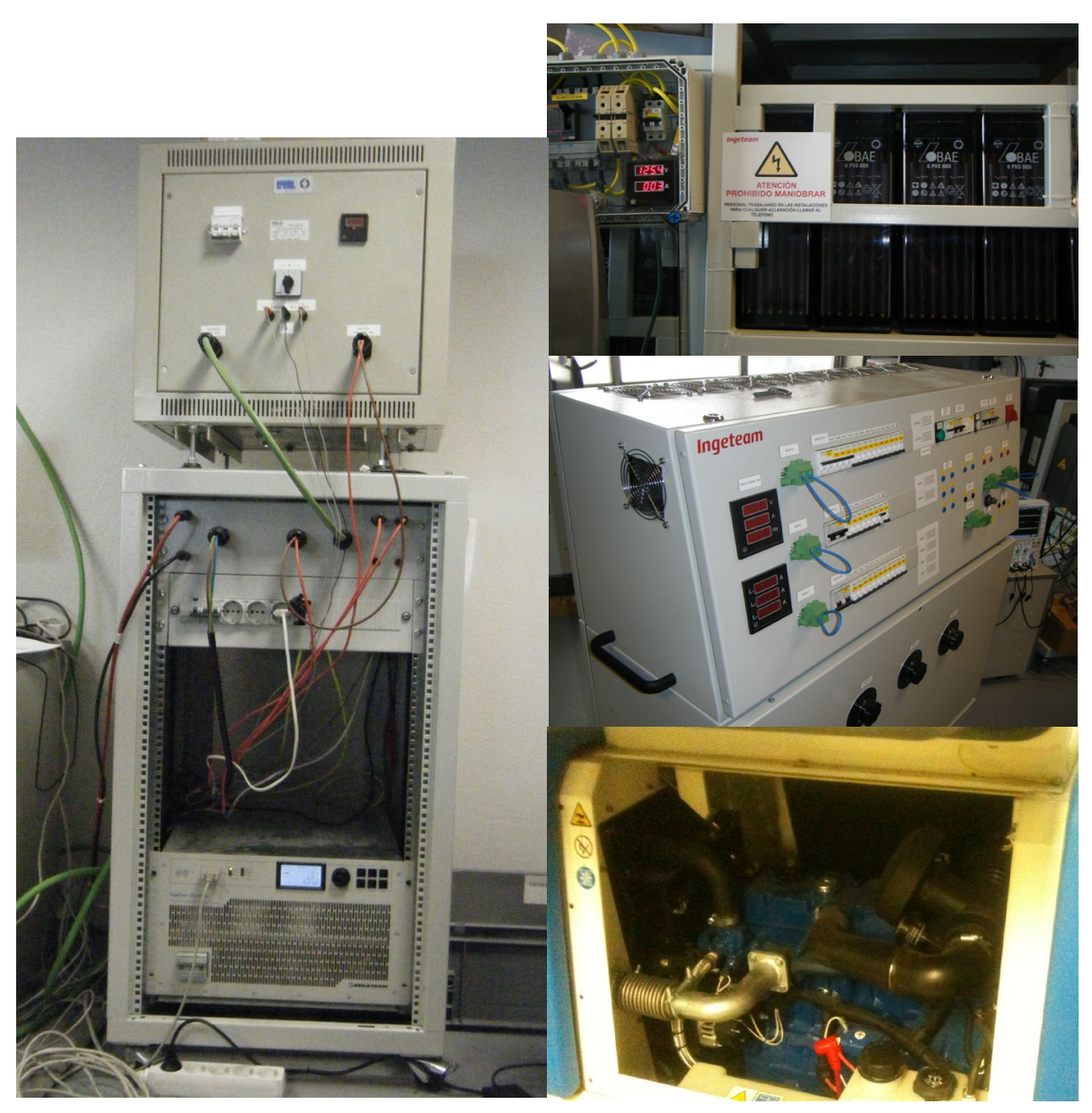

Fig. 14. PV emulator, battery inverter, PV inverter, battery bank and load bank used for the experimental setup.

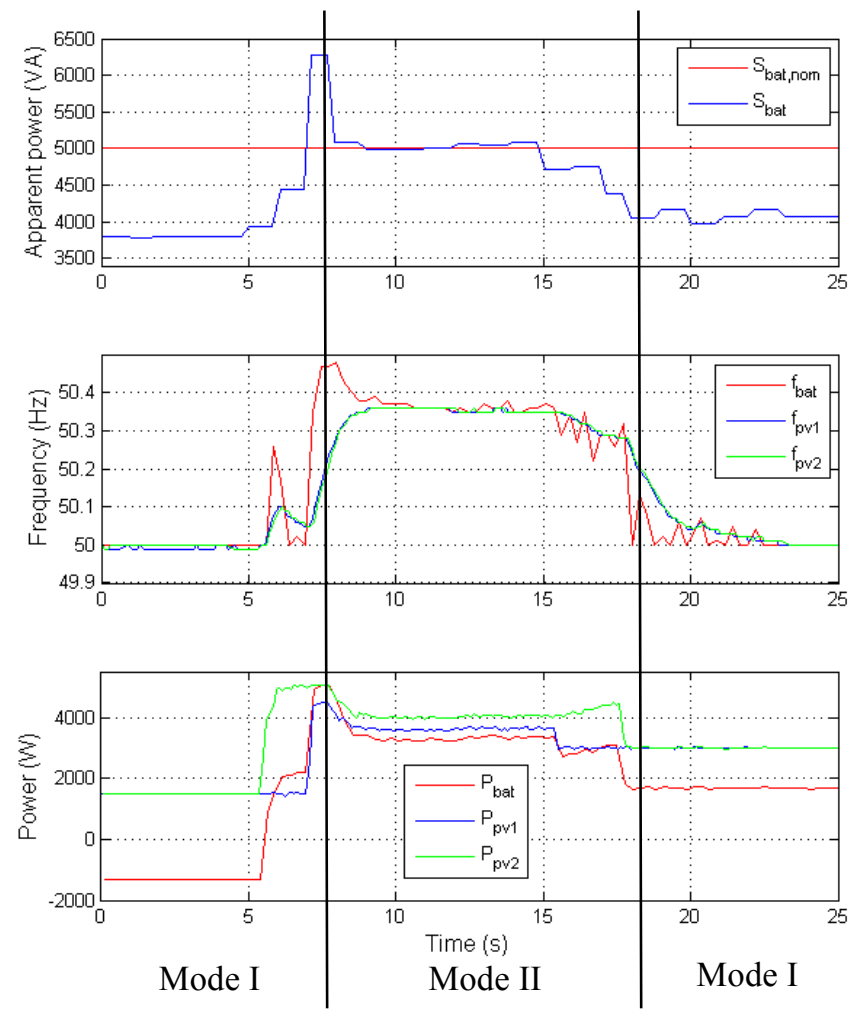

Fig. 15. Experimental results for the over-current protection. 
In the second test, the battery voltage control was verified. The test conditions were similar to those of the second part of the first simulation (see section 5, switch from mode I to mode II and back to mode I). The experimental results are shown in Fig. 16. The first graph shows $v^{*}{ }_{b a t}=147 \mathrm{~V}$ and $v_{\text {bat }}$ whilst the other graphs represent the same variables as for the previous test. At the start, the system was operating in mode I and the PV arrays were delivering the MPP power. Then, a load with $P_{\text {load }}=4.3 \mathrm{~kW}$ and $Q_{\text {load }}=3.4 \mathrm{kVAr}$ was disconnected. As a result, the battery absorbed a higher current and its voltage increased to above absorption voltage $v^{*}$ bat . According to the control of Fig. 4, the battery inverter increased the frequency. This led to a PV power reduction, making it possible to control the battery voltage to its reference value. Some seconds later there was an irradiance drop, the battery voltage and therefore the frequency decreased, the system switched to mode I and the PV inverters changed to MPPT. In this test, a load with $S_{\text {load }}=5.5 \mathrm{kVA}$, which was even higher than $S_{\text {bat, nom }}$, was instantly disconnected. For such a critical situation, it was shown how the voltage control performed correctly, preventing the battery from overcharging.

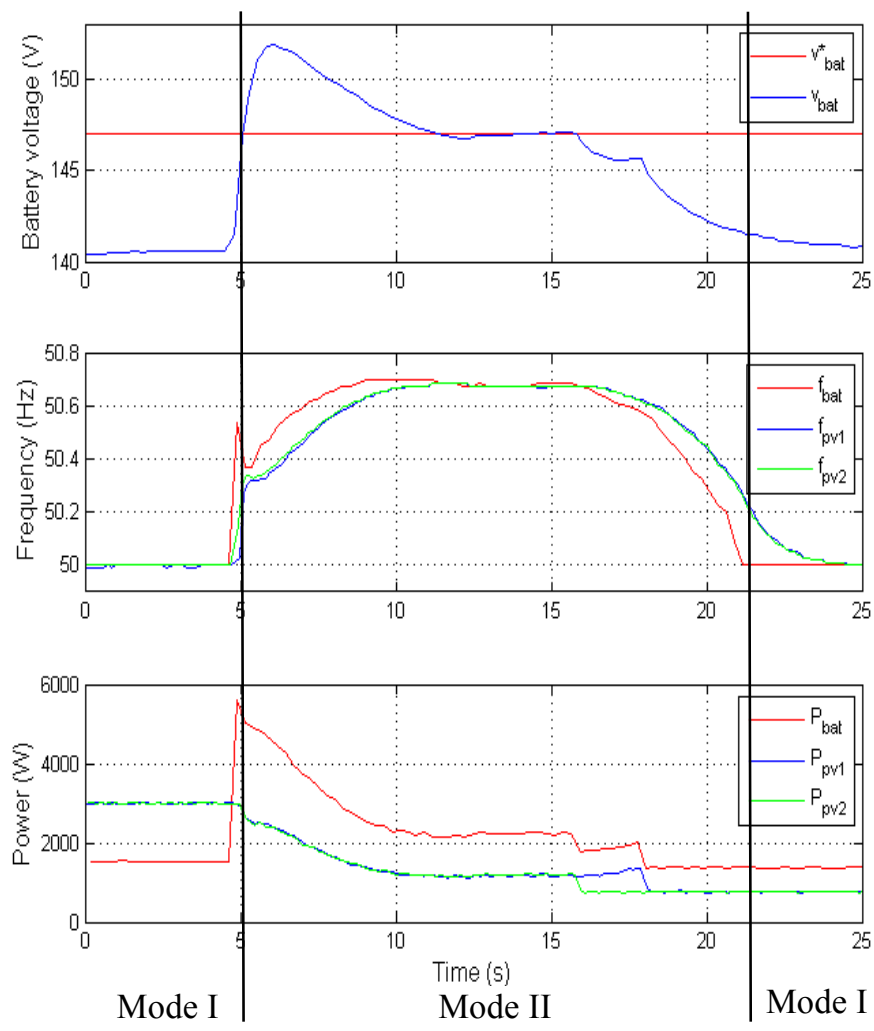

Fig. 16. Experimental results for the overcharge protection.

In the third test, the diesel generator management was verified. The test conditions were similar to those of the second simulation (see section 5). The experimental results are shown in Fig. 17. Powers $P_{b a t}, P_{p v 1}, P_{p v 2}$ and $P_{\text {diesel }}$ are shown in the first graph, and the apparent powers $S_{\text {bat,nom }}=S_{\text {diesel, nom }}, S_{\text {bat }}$ and $S_{\text {disel }}$ are plotted in the second graph. Initially, the system operated in mode I. Since consumption was higher than generation, the battery was discharging. When the battery SOC fell below $\mathrm{SOC}_{\mathrm{on}}$, the diesel generator was connected and the system switched to mode III. Then, the battery inverter demanded $P_{\text {available }}$ (see 20), which made the diesel generator operate at its rated power $S_{\text {diesel }}=5 \mathrm{kVA}$. Some seconds later, the irradiance increased. As a result, $P_{\text {available }}$ became too high and the battery inverter demanded its rated power, leading to a reduction in the diesel apparent power. Then, the irradiance increased again. Since the battery inverter was unable to absorb more power, the diesel generator power became negative and was disconnected, leading to mode I. This mode is not shown in the figure because it is very short. The diesel disconnection led to an over-current in the battery inverter, which therefore increased the frequency and the system switched to mode II. This resulted in a PV power reduction and in 
a limitation of the battery inverter current. With this test, it can be observed that the diesel generator management strategy made it operate at its rated power for as long as possible and protected it from absorbing power. This optimized the diesel generator efficiency and duty cycle.

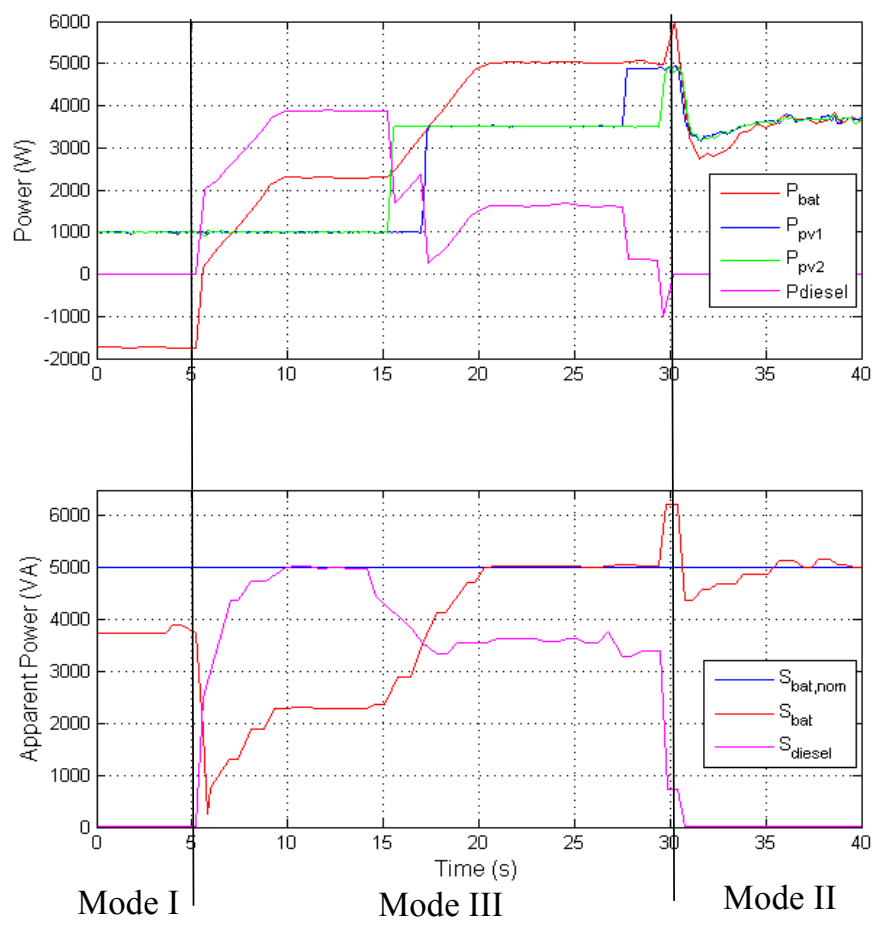

Fig. 17. Experimental results for the diesel generator management.

\section{CONCLUSION}

This paper develops an energy management strategy for a stand-alone system in which the battery and the diesel generator are centralized and generate the grid whilst the loads and the PV generators are distributed and connected to the grid.

During normal operation, the diesel generator is not connected and the battery absorbs the difference between generation and consumption. Whenever the battery is fully charged or the battery power exceeds its nominal value, then the PV power should be limited. In order to transmit this information, the battery inverter increases the frequency, which is detected by the PV generators. As a result, the PV power is continuously reduced in order to control the battery voltage or battery current to the maximum value. The use of frequency means that communication cables are unnecessary, making the system simpler, cheaper and more reliable. The control is fast and stable enough for any situation, preventing the battery from overcharge and over-current, improving its expected life and making it possible to install a PV power higher than the battery inverter rated power. On the other hand, when the State of Charge of the battery is low, the diesel generator is connected. Here, the strategy makes the diesel generator operate at its rated power as far as possible, optimizing its efficiency and expected life.

Furthermore, this energy management strategy makes it possible to supply the loads in case of battery failure. Whilst the strategy is based on the battery inverter, the battery is also the most vulnerable element. If the battery is broken down, the diesel generator is connected and generates the grid whereas the PV inverters operate under MPPT. In this mode, if the PV power becomes higher than the load power, the diesel generator will absorb power. As a result, the grid frequency will increase and the PV power will be reduced, which ensures correct system operation. 
Simulation and experimental results were obtained for a system with a $10 \mathrm{~kW}$ PV generation, a $5 \mathrm{kVA}$ battery inverter, a $5 \mathrm{kVA}$ diesel generator and a $5 \mathrm{kVA}$ load, validating the energy management strategy for the most critical situations.

\section{ACKNOWLEDGEMENT}

This work was partially funded by the Spanish Ministry of Economy and Competitiveness under Grants DPI2009-14713-C03-01 and DPI2010-21671-C02-01, by the Government of Navarra and the FEDER funds under project "Microgrids in Navarra: design and implementation" and by the Public University of Navarra.

\section{REFERENCES}

[1] D. P. Kaundinya, P. Balachandra, N. H. Ravindranath. Grid-connected versus stand-alone energy systems for decentralized power-A review of literature. Renewable and Sustainable Energy Reviews 2009; 13: 2041-2050.

[2] K. Bandara, T. Sweet, J. Ekanayake. Photovoltaic applications for off-grid electrification using novel multi-level technology with energy storage. Renewable Energy 2012; 37: 8288.

[3] S. K. Pandey, S. R. Mohanty, N. Kishor. A literature survey on load-frequency control for conventional and distribution generation power systems. Renewable and Sustainable Energy Reviews 2013; 25: 318-334.

[4] H. Shayeghi, H. A. Shayanfar, A. Jalili. Load frequency control strategies: A state-of-theart survey for the researcher. Energy Conversion and Management 2009; 50: 344-353.

[5] I. Ngamroo, Y. Mitani, K. Tsuji. Application of SMES coordinated with solid-state phase shifter to load frequency control. IEEE Transactions on Applied Superconductivity 1999; 9 (2): 322-325.

[6] I. Ngamroo, Y. Mitani, K. Tsuji. Robust load frequency control by solid-state phase shifter based on $\mathrm{H}_{\infty}$ control design. IEEE Power Engineering Society Winter Meeting 1999: 725-730.

[7] M. Aldeen, J. F. Marsh. Decentralized proportional-plus-integral control design method for interconnected power systems. Proceedings of Institute of Electrical Engineering 1991; 138 (4): 263-274.

[8] H. Xin, Y. Liu, Z. Wang, D. Gan, T. Yang. A new frequency regulation strategy for photovoltaic systems without energy storage. IEEE Transactions on Sustainable Energy 2013; 4 (4): 985-993.

[9] A. Hoke, D. Maksimovic. Active power control of photovoltaic power systems. IEEE Conference on Technologies for Sustainability 2013: 70-77.

[10] L. D. Watson, J. W. Kimball. Frequency regulation of a microgrid using solar power. IEEE Applied Power Electronics Conference and Exposition 2011: 321-326.

[11] M. Datta, T. Senjyu, A. Yona, T. Funabashi, C. Kim. A frequency-control approach by photovoltaic generator in a PV-diesel hybrid power system. IEEE Transactions on Energy Conversion 2011; 26 (2): 559-571.

[12] R. Langella, G. Margiotta, D. Proto, A. Testa. Hybrid PV-diesel stand-alone system sizing for remote microgrids. Energy Conference and Exhibition (ENERGYCON) 2012: 475-482.

[13] P. Bajpai, V. Dash. Hybrid renewable energy systems for power generation in stand-alone applications: A review. Renewable and Sustainable Energy 2012; 16: 2926-2939.

[14] E. S. Hrayshat. Techno-economic analysis of autonomous hybrid photovoltaic-dieselbattery system. Energy for Sustainable Development 2009; 13: 143-150.

[15] S. Rehman, L.M. Al-Hadhrami. Study of a solar PV-diesel-battery hybrid power system for remotely located population near Rafha, Saudi Arabia. Energy 2010; 35: 4986-4995. 
[16] J. K. Kaldellis. An integrated model for performance simulation of hybrid wind-diesel systems. Renewable Energy 2007; 32: 1544-1564.

[17] A. A. Setiawan, Y. Zhao, C. V. Nayar. Design, economic analysis and environmental considerations of mini-grid hybrid power system with reverse osmosis desalination plant for remote areas. Renewable Energy 2009; 34: 374-383.

[18] J. H. Jeon, J. Y. Kim, S. K. Kim, J. M. Kim. Unified compensation control of a hybrid storage system for enhancing power quality and operation efficiency in a diesel and windturbine based stand-alone microgrid. Symposium on Power Electronics for Distributed Generation Systems (PEDG) 2012: 264-270.

[19] L. A. S. Ribeiro, O. R. Saavedra, S. L. Lima, J. G. Matos, G. Bonan. Making isolated renewable energy systems more reliable. Renewable Energy 2012; 45: 221-231.

[20] H. Ghoddami, M. B. Delghavi, A. Yazdani. An integrated wind-photovoltaic-battery system with reduced power-electronic interface and fast control for grid-tied and off-grid applications. Renewable Energy 2012; 45: 128-137.

[21] A. K. Daud, M. S. Ismail. Design of isolated hybrid systems minimizing costs and pollutant emissions. Renewable Energy 2012; 44: 215-224.

[22] F. Valenciaga, P. F. Puleston. Supervisor control for a stand-alone hybrid generation system using wind and photovoltaic energy. IEEE Transactions on Energy Conversion 2005; 20 (2): 398-405.

[23] Z. Liao, X. Ruan. A novel power management control strategy for stand-alone photovoltaic power system. Power Electronics and Motion Conference 2009: 445-449.

[24] D. B. Cândido, L. Michels, H. L. Hey. Integrated control of a stand-alone photovoltaic system based on decentralized DC-DC converters. Symposium on Industrial Electronics (ISIE) 2010: 213-218.

[25] S. G. Tesfahunegn, P. J. S. Vie, O. Ulleberg, T. M. Undeland. A simplified battery charge controller for safety and increased utilization in stand-alone PV applications. Conference on Clean Electric Power (ICCEP) 2011: 137-144.

[26] B. S. Manju, R. Ramaprabha, B. L. Mathur. Modelling and control of standalone solar photovoltaic charging system. Conference on Emerging Trends in Electrical and Computer Technology (ICETECT) 2011: 78-81.

[27] N. Eghtedarpour, E. Farjah. Control strategy for distributed integration of photovoltaic and energy storage systems in DC micro-grids. Renewable Energy 2012; 45: 96-110.

[28] S. Jiang, W. Wang, H. Jin, D. Xu. Power management strategy for microgrid with energy storage system. Conference on IEEE Industrial Electronics Society 2011: 1524-1529.

[29] K. O. Oureilidis, C. S. Demoulias. Microgrid wireless energy management with energy storage system. Universities Power Engineering Conference (UPEC) 2012: 1-6.

[30] A. Tuladhar. Power management of an off-grid PV inverter system with generators and battery banks. IEEE Power \& Energy Society General Meeting 2011: 1-5.

[31] J. M. Guerrero, J. C. Vasquez, J. Matas, L. G. Vicuña, M. Castilla. Hierarchical control of droop-controlled ac and dc microgrids- A general approach toward standardization. IEEE Transactions on Industrial Electronics 2011; 58 (1): 158-172.

[32] S. Kuszmaul, S. Gonzalez, A. Ellis, E. Serban. Commanding inverters to establish coordinated $\mu$ grid functionality at Sandia National Laboratories. IEEE Photovoltaic Specialists Conference 2009: 1513-1518.

[33] A. Mohd, E. Ortjohann, D. Morton, O. Omari. Review of control techniques for inverters parallel operation. Electric Power Systems Research 2010; 80 (12), 1477-1487.

[34] S. Sanchez, M. Molinas, M. Degano, P. Zanchetta. Stability evaluation of a DC microgrid and future interconnection to an AC system. Renewable Energy 2014: 62: 649-656.

[35] S. Armstrong, M. E. Glavin, W. G. Hurley. Comparison of battery charging algorithms for stand alone photovoltaic systems. IEEE Power Electronics Specialists Conference (PESC) 2008: 1469-1475.

[36] B. J. Huang, P. C. Hsu, M. S. Wu, P. Y. Ho. System dynamic model and charging control of lead-acid battery for stand-alone solar PV system. Solar Energy 2010; 84: 822-830. 
[37] X. Li, J. Li, L. Xu, M. Ouyang, X. Han, L. Lu, C. Lin. Online management of lithium-ion battery based on time-triggered controller area network for fuel-cell hybrid vehicle applications. Journal of Power Sources 2010; 195: 3338-3343.

[38] A. Urtasun, P. Sanchis, L. Marroyo. Adaptive voltage control of the dc/dc boost stage in PV converters with small input capacitor. IEEE Transactions on Power Electronics 2013; 28 (11): 5038-5048.

[39] A. Urtasun, P. Sanchis, L. Marroyo. Limiting the power generated by a photovoltaic system. Multi-Conference on Systems, Signals and Devices (SSD) 2013: 1-6.

[40] K. Jalili, S. Bernet. Design of LCL filters of active-front-end two-level voltage-source converters. IEEE Transactions on Industrial Electronics 2009; 56 (5): 1674-1689. 